\title{
AVALIAÇÃO DE AGROTÓXICOS EM SOLO DE SISTEMAS DE PRODUÇÃO AGRÍCOLA CONVENCIONAL E AGROECOLÓGICO
}

\author{
Fernanda G. Morro ${ }^{\mathrm{a}}$ e Danielle C. Schnitzler, ${ }^{\mathrm{a}, *(1)}$ \\ a'Departamento Acadêmico de Química e Biologia, Universidade Tecnológica Federal do Paraná, 81280-340 Curitiba - PR, Brasil
}

Recebido em 29/01/2021; aceito em 22/04/2021; publicado na web em 12/05/2021

\begin{abstract}
EVALUATION OF AGROCHEMICALS IN SOIL OF CONVENTIONAL AND AGROECOLOGICAL AGRICULTURAL PRODUCTION SYSTEMS. At the Contestado Settlement, Lapa, PR, soil samples from agroecological and conventional environments were evaluated against the agrochemicals alachlor, atrazine, chlorpyrifos and trifluralin. For sampling, 3 depths were considered, 10 points were selected, 5 in an agroecological and 5 in the conventional environment, with sampling frequency was at 2-month intervals. The samples were characterized according to textural, chemical and fertility parameters and the data were used in the chemometric study (PCA) demonstrating that the environments are different. The method of extraction, identification and quantification was validated at the trace level. The analytes were analyzed by GC-MS/MS, the recovery values were between 83 to $113 \%$, RSD less than $14 \%$, LD equal to $0.01 ; 0.0028 ; 0.004$ and $002 \mu \mathrm{g} \mathrm{kg}^{-1}$, LQ equal to $0.04 ; 0.008 ; 0.011$ and $0.05 \mu \mathrm{g} \mathrm{kg}^{-1}$, for alachlor, atrazine, chlorpyrifos and trifluralin, respectively. Chlorpyrifos was identified in the Conv3 and trifluralin in the Agro2 and 3 and Conv 2 environments. Therefore, the application of pesticides in conventional environments can contaminate agroecological environments. The effect of rain/precipitation on the samples was evaluated by simulation and it was found that the physical-chemical properties of the compounds and the soil have an influence on their behavior in the soil profile.
\end{abstract}

Keywords: soil; agrochemicals; GC-MS/MS; agroecological system; conventional system.

\section{INTRODUÇÃO}

Em termos de cultivo de alimentos, na produção convencional pode utilizar da aplicação de agrotóxicos às plantas e/ou ao solo, em pequena ou larga escala, enquanto que na produção agroecológica e orgânica tais compostos não são utilizados, uma vez que temse como objetivo o equilíbrio entre plantas, solos, nutrientes, luz solar, umidade e organismos coexistentes, de forma a preservar e ampliar a biodiversidade, além de contribuir com vários benefícios sociais e econômicos aos agricultores. ${ }^{1,2}$ A mudança do sistema convencional para o agroecológico traz para o campo a discussão de que a agricultura sustentável é possível, a partir de práticas que considerem as diretrizes básicas de sustentabilidade. ${ }^{3}$ A partir do auxílio de cooperativas que atuam na agroindústria e no comércio, os alimentos podem receber certificações que condizem com as normas e regularizações internacionais para alimentos orgânicos e, assim, podem ser comercializados, garantindo recursos econômicos para os produtores.

No entanto, devido à contaminação ambiental generalizada, as práticas de agricultura orgânica não podem garantir a ausência total de resíduos potencialmente tóxicos, devido ao fato de alguns compostos terem alta mobilidade em solos e na atmosfera, quando se considera a existência de áreas de sistemas de plantio convencional e agroecológico que situam-se em regiões próximas. ${ }^{4} \mathrm{~A}$ importância de avaliar tais compostos do sistema convencional, é que estes podem ser transportados por alguns mecanismos para o sistema agroecológico, fazendo com que o mesmo deixe de ser considerado um sistema de produção isento de quaisquer resíduos de agrotóxicos.

Os agrotóxicos voláteis podem ser transportados de um ambiente para outro sob ação dos ventos, uma vez que ficam presentes na atmosfera. Considerando agrotóxicos que apresentam caráter ionizável, há a possibilidade de os compostos sofrerem lixiviação, podendo atingir as camadas mais profundas do solo e, possivelmente,

*e-mail: daniellec@utfpr.edu.br o lençol freático, contaminando águas superficiais e subterrâneas. Ainda considerando o transporte de agrotóxicos ao longo do perfil do solo, é possível que tais contaminantes sejam deslocados em decorrência das diferenças de relevo e declividade.

Dentro desse contexto, a área de estudo está situada no município da Lapa, Estado do Paraná, onde encontra-se o denominado Assentamento Contestado. O Assentamento Contestado - assim conhecido em homenagem às famílias de trabalhadores rurais que lutaram na Guerra do Contestado, que ocorreu entre os anos de 1912 a 1916 - foi conquistado através da luta do Movimento dos Trabalhadores Rurais Sem Terra (MST, organização existente desde 1984) no dia 7 de fevereiro de 1999, quando 52 famílias da região de Curitiba, Balsa Nova, Lapa e outras regiões do Paraná ocuparam a antiga Fazenda Santa Amélia em um processo pacífico que reivindicou a terra para a reforma agrária, beneficiando, inicialmente, 108 famílias. ${ }^{2,5,6} \mathrm{~A}$ fazenda pertencia ao grupo Incepa, empresa produtora de cerâmica que havia adquirido o local como área de reflorestamento para produção de lenha, principalmente de eucaliptos e pinus, para a queima durante o processo de secagem da cerâmica produzida. ${ }^{7}$ Com as inovações tecnológicas, o interesse pela matéria prima da madeira como lenha passou a ser ultrapassada, permanecendo durante muitos anos uma região improdutiva. O Assentamento foi liberado pelo INCRA em 29/11/2000. Atualmente, a comunidade do Assentamento Contestado é constituída por, pelo menos, 156 famílias, que produzem alimentos durante o ano todo, resultando em uma diversidade de produtos, incluindo frutas, verduras, legumes e hortaliças. Além disso, os assentados também praticam a atividade pecuária, com criação de vacas, porcos e frangos, assim como atividade de piscicultura. ${ }^{2}$ Tais atividades são realizadas tanto por produtores que utilizam o sistema convencional quando por aqueles que utilizam o sistema agroecológico de produção de alimentos. Os alimentos de produção agroecológica são certificados, de forma participativa, pela Rede Ecovida, para posterior comércio.

O tipo de solo presente no Assentamento Contestado pertence à classe dos Cambissolos. Os cambissolos normalmente apresentam condições desfavoráveis para produção agrícola, pois possuem altos 
teores de silte e caulinita fazendo com que apresentem resistência à infiltração da água e lixiviação ao longo do perfil do solo. ${ }^{8}$ Contudo, o sistema de sucessão e de rotação de culturas, juntamente com o alto aporte de resíduos vegetais e animais, auxiliam no aumento de matéria orgânica do solo, além do uso de palhas sobre o solo, que permite conservá-lo, minimizando as variações de temperatura, mantendo a umidade e evitando o crescimento de plantas daninhas. ${ }^{9}$

A rotação de culturas, que é praticada pelos produtores do Assentamento Contestado, ajuda a conservar e proteger o solo, uma vez que ocorre a alternância de pragas animais e vegetais. Além de aumentar a produtividade, a rotação de culturas permite melhorar as características físicas, químicas e biológicas do solo. Entretanto, quando se tem a necessidade de aplicação de agrotóxicos às plantas e/ou ao solo, sabe-se que para cada gama de culturas e pragas existem agrotóxicos que podem ser utilizados, o que torna possível que concentrações traço de diferentes agrotóxicos fiquem retidas no solo e ainda podendo ser absorvidas por outra planta que será posteriormente cultivada no mesmo solo.

Para avaliação da presença de agrotóxicos em solo, é necessário ter-se conhecimento das características do solo e das substâncias contaminantes em questão. As propriedades intrínsecas do solo podem ser determinadas a partir de diferentes estudos de caracterização. A identificação e a quantificação de espécies de agrotóxicos presentes em amostras de solo também podem ser estudadas, além da avaliar o comportamento dos agrotóxicos para inferir sobre a possível mobilidade dos compostos na matriz.

Neste trabalho os analitos estudados foram: alaclor, atrazina, clorpirifós e trifluralina. O alaclor é um herbicida organoclorado, podendo ser utilizado nas culturas de milho, soja, cana-de-açúcar, e tem seu registo cancelado no estado do Paraná, Brasil, desde o ano de 2013; apresenta tempo de meia vida $\left(t_{1 / 2}\right)$ de 14-80 dias, alta solubilidade em água $\left(240,0 \mathrm{mg} \mathrm{L}^{-1}\right)$ e baixo valor de coeficiente de sorção à matéria orgânica do solo $\left(\mathrm{k}_{\mathrm{oc}} 103,0 \mathrm{~mL} \mathrm{~g}{ }^{-1}\right) \cdot{ }^{10-13}$ Atrazina, um herbicida da classe das triazinas, é muito utilizado nas culturas de milho, soja e cana-de-açúcar. É um composto ionizável e pode sofrer degradação microbiana, $\mathrm{t}_{1 / 2}$ de 60 dias, $33,0 \mathrm{mg} \mathrm{L}^{-1}$ de solubilidade em água, e $\mathrm{k}_{\mathrm{oc}}$ igual a $133,4 \mathrm{~mL} \mathrm{~g}^{-1} \cdot{ }^{10,14,15} \mathrm{O}$ clorpirifós é um inseticida organofosforado, muito utilizado em cultura de soja, milho, café, tomate e morango, $\mathrm{t}_{1 / 2}$ de 30 dias, $0,4 \mathrm{mg} \mathrm{L}^{-1}$ de solubilidade em água e $\mathrm{k}_{\mathrm{oc}}$ igual a $6070 \mathrm{~mL} \mathrm{~g}^{-1} .^{10,16}$ Trifluralina, é um herbicida pertencente à classe das dinitroanilinas, também muito utilizada em soja, milho e cana-de-açúcar, apresenta de 45-60 dias de $\mathrm{t}_{1 / 2}, 0,3 \mathrm{mg} \mathrm{L} \mathrm{L}^{1} \mathrm{de}$ solubilidade em água e $\mathrm{k}_{\mathrm{oc}}$ igual a $8000 \mathrm{~mL} \mathrm{~g}^{-1} .^{10,12,17,18}$

Existem estudos acerca da determinação de alaclor, atrazina, clorpirifós e trifluralina em diferentes frutas, hortaliças e vegetais. Um deles é o Programa de Análise de Resíduos de Agrotóxicos em Alimentos (PARA) da Agência Nacional de Vigilância Sanitária (Anvisa), que tem como atividade monitorar resíduos de agrotóxicos em alimentos. O Programa registrou, entre os anos de 2013 a 2015, a detecção de 48 agrotóxicos em 157 amostras de morango, sendo que $65 \%$ dos agrotóxicos detectados não são autorizados, porém, são utilizados inadequadamente pelos produtores, para a cultura de morango, como o clorpirifós que apresentou concentração superior a $0,01 \mathrm{mg} \mathrm{kg}^{-1}$ nas amostras. ${ }^{19}$ Nesse sentido, fica demonstrado a importância da avaliação de diferentes agrotóxicos mesmo em culturas em que não são utilizados

Para a avaliação simultânea de diferentes agrotóxicos em solo, faz-se necessário o desenvolvimento de método que possa identificar e quantificar, de forma segura, os analitos presentes na matriz. Esse processo, denominado validação de método, requer diferentes figuras de mérito que são avaliadas em ensaios de fortificação em diferentes níveis de concentração. A técnica de análise é selecionada com base no nível de concentração que se deseja quantificar.
Dessa forma, o presente estudo foi realizado com amostras de solo que foram coletadas de uma região agrícola da cidade de Lapa, Paraná, Brasil, na qual faz-se a produção de alimentos, concomitantemente, de forma convencional e agroecológica. Devido à possível contaminação entre as diferentes matrizes ambientais, o estudo teve como objetivo avaliar a presença dos agrotóxicos alaclor, atrazina, clorpirifós e trifluralina, através da determinação das possíveis diferenças entre amostras de solo agrícola dos sistemas agroecológico e convencional a partir de caracterização das amostras, correlacionar suas características intrínsecas às possíveis interações com os agrotóxicos, e avaliação do comportamento dos agrotóxicos no solo.

\section{PARTE EXPERIMENTAL}

\section{Amostragem}

O Assentamento Contestado fica localizado a $62,3 \mathrm{~km}$ do centro da cidade de Curitiba, Paraná, e é composto por 10 lotes, de 10 a 15 ha cada um, totalizando aproximadamente 3228 ha, considerando também a área de reserva natural. A partir da análise cartográfica e de pesquisas em campo, realizou-se a seleção de 5 pontos agroecológicos e 5 pontos convencionais, em que foram coletadas as amostras de solo.

A Tabela 1 apresenta as coordenadas dos 10 pontos amostrais, que foram identificados de acordo com o tipo de produção de alimentos. Todos os pontos amostrais foram demarcados pelo GPS com o uso de sonda multiparâmetros HI9829, Hanna Instruments. A distribuição dos pontos amostrais é apresentada na Figura $1 \mathrm{~S}$ no Material Suplementar.

Foram realizadas 3 campanhas de amostragem, com 2 meses de intervalo entre si. Para cada ponto de amostragem foi realizada a coleta em 3 profundidades: (i) superfície, utilizando uma pá de alumínio (ii) $0-20 \mathrm{~cm}$ e (iii) $20-40 \mathrm{~cm}$, utilizando um trado holandês, de acordo com o Manual de procedimentos de coleta de amostras de Solo da Embrapa. ${ }^{20}$ As amostras de solo de sistemas agroecológicos foram coletadas onde se faz rotação de culturas, de forma que diferentes culturas foram cultivadas no mesmo local, dentre elas: brócolis, beterraba, alho, coentro, alface, repolho, cebolinha, milho, mandioca, etc. É importante ressaltar que diferentes culturas foram cultivadas no mesmo local, de acordo com fatores climáticos que permitem isso. No sistema convencional, as amostras foram coletadas em plantações de morango, fruto que é cultivado em todos os sistemas convencionais selecionados, de modo a permitir uma comparação entre os resultados.

As amostras de solo coletadas ficaram armazenadas em frascos de vidro, previamente limpos, em caixa térmica com gelo até o transporte ao laboratório. No laboratório, as amostras ficaram armazenadas em freezer à $-18^{\circ} \mathrm{C}$.

\section{Caracterização das amostras de solo}

Todos os procedimentos de caracterização foram realizados para as amostras dos 10 pontos amostrais, considerando as 3 profundidades de coleta, totalizando 30 amostras. O solo utilizado para a caracterização foi seco em estufa, 1 a $50{ }^{\circ} \mathrm{C}$ por $48 \mathrm{~h}$. Todas as amostras foram suavemente maceradas e peneiradas em malha de $2 \mathrm{~mm}$, identificadas e armazenadas em sacos plásticos. ${ }^{21}$ Para a caracterização, foram avaliados o $\mathrm{pH}$, cátions trocáveis, quantificação de P, K, N, C orgânico e C total, teores de areia, silte e argila.

\section{$p H$}

Transferiram-se $10 \mathrm{~g}$ de solo para um frasco plástico, e adicionouse $25 \mathrm{~mL}$ de $\mathrm{CaCl}_{2} 0,01 \mathrm{~mol} \mathrm{~L}^{-1}$. A solução foi agitada por $15 \mathrm{~min}$, em $240 \mathrm{rpm}$, e ficou em repouso por $40 \mathrm{~min}$. A medida foi realizada 
Tabela 1. Coordenadas geográficas dos 10 pontos amostrais da área de estudo - Lapa, obtidas por sonda multiparâmetros

\begin{tabular}{|c|c|c|c|c|c|}
\hline \multirow{2}{*}{ Sistema de produção } & \multirow{2}{*}{$\begin{array}{l}\text { Identificação dos pontos } \\
\text { amostrais }\end{array}$} & \multirow{2}{*}{$\begin{array}{c}\text { Identificação numérica } \\
\text { das amostras }\end{array}$} & \multicolumn{2}{|c|}{ Coordenadas } & \multirow{2}{*}{ Altitude do ponto / (m } \\
\hline & & & Latitude & Longitude & \\
\hline \multirow{5}{*}{ Agroecologia } & Agro1 & $1,2,3$ & $-25^{\circ} 38^{\prime} 27,70^{\prime \prime}$ & $-49^{\circ} 41^{\prime} 46,10^{\prime \prime}$ & 963 \\
\hline & Agro2 & $4,5,6$ & $-25^{\circ} 38^{\prime} 23,10^{\prime \prime}$ & $-49^{\circ} 42^{\prime} 33,80^{\prime \prime}$ & 943 \\
\hline & Agro3 & $7,8,9$ & $-25^{\circ} 38,7^{\prime} 29^{\prime \prime}$ & $-49^{\circ} 43^{\prime} 12,42^{\prime \prime}$ & 928 \\
\hline & Agro4 & $10,11,12$ & $-25^{\circ} 37^{\prime} 12,10^{\prime \prime}$ & $-49^{\circ} 43^{\prime} 42,20^{\prime \prime}$ & 917 \\
\hline & Agro5 & $13,14,15$ & $-25^{\circ} 37^{\prime} 5,16^{\prime \prime}$ & $-49^{\circ} 41^{\prime} 37,04^{\prime \prime}$ & 951 \\
\hline \multirow{5}{*}{ Convencional } & Conv1 & $16,17,18$ & $-25^{\circ} 38^{\prime} 43,70^{\prime \prime}$ & $-49^{\circ} 42^{\prime} 21,70^{\prime \prime}$ & 958 \\
\hline & Conv2 & $19,20,21$ & $-25^{\circ} 38^{\prime} 31,70^{\prime \prime}$ & $-49^{\circ} 44^{\prime} 13,30^{\prime \prime}$ & 873 \\
\hline & Conv3 & $22,23,24$ & $-25^{\circ} 37^{\prime} 57,40^{\prime \prime}$ & $-49^{\circ} 43^{\prime} 53,40^{\prime \prime}$ & 900 \\
\hline & Conv4 & $25,26,27$ & $-25^{\circ} 37^{\prime} 39,30^{\prime \prime}$ & $-49^{\circ} 43^{\prime} 15,40^{\prime \prime}$ & 934 \\
\hline & Conv5 & $28,29,30$ & $-25^{\circ} 36^{\prime} 51,60^{\prime \prime}$ & $-49^{\circ} 42^{\prime} 32,60^{\prime \prime}$ & 932 \\
\hline
\end{tabular}

com um potenciômetro previamente calibrado com soluções padrão de $\mathrm{pH} 7,0$ e $4,0 .{ }^{21}$

\section{Cátions trocáveis $\left(\mathrm{Al}^{3+}, \mathrm{Ca}^{2+} e \mathrm{Mg}^{2+}\right)$}

A Capacidade de Troca de Cátions (CTC) de solos é medida a partir da quantificação dos elementos $\mathrm{Al}^{3+}, \mathrm{Ca}^{2+}, \mathrm{Mg}^{2+} \mathrm{e} \mathrm{K}^{+}$, que são os

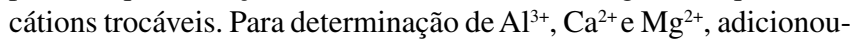
se, em $10 \mathrm{~g}$ de solo, $125 \mathrm{~mL}$ de $\mathrm{KCl} 1 \mathrm{~mol} \mathrm{~L}^{-1}$, agitou-se por $5 \mathrm{~min}$ e deixou-se em repouso por uma noite. Utilizaram-se $20 \mathrm{~mL}$ dessa solução para determinação de $\mathrm{Al}^{3+}, 20 \mathrm{~mL}$ para $\mathrm{Ca}^{2+}$ e $20 \mathrm{~mL}$ para $\mathrm{Ca}^{2+}$ e $\mathrm{Mg}^{2+}$, como é apresentado a seguir. ${ }^{21}$

\section{Determinação de $\mathrm{Al}^{3+}$}

Adicionaram-se 3 gotas do indicador azul de bromotimol a $20 \mathrm{~mL}$ do extrato, e titulou-se com solução de $\mathrm{NaOH} 0,02 \mathrm{~mol} \mathrm{~L}^{-1}$, até viragem da cor de amarelo-cítrico para azul. A quantidade de $\mathrm{Al}^{3+}$ em $\mathrm{cmol}_{\mathrm{c}} \mathrm{dm}^{-3}$ é dada pelo volume de $\mathrm{NaOH}$ em mL utilizado na titulação. ${ }^{21}$

\section{Determinação de $\mathrm{Ca}^{2+}$}

Adicionaram-se, a $20 \mathrm{~mL}$ de extrato, $4 \mathrm{~mL}$ de solução tampão a pH igual a 12,0. Adicionou-se calconcarbonato e sulfato de sódio à solução e titulou-se com solução EDTA $0,01 \mathrm{~mol} \mathrm{~L}^{-1}$, até viragem de cor rosa para azul-roxo. $\mathrm{O}$ volume em $\mathrm{mL}$ utilizado de EDTA é equivalente à quantidade de $\mathrm{Ca}^{2+} \mathrm{em} \mathrm{cmol}_{\mathrm{c}} \mathrm{dm}^{-3} \cdot{ }^{21}$

\section{Determinação de $\mathrm{Ca}^{2+} e \mathrm{Mg}^{2+}$ totais}

As análises de $\mathrm{Ca}$ e $\mathrm{Mg}$ totais foram realizadas utilizando $20 \mathrm{~mL}$ do extrato, em espectrômetro de absorção atômica em chama, Varian, com prévia calibração do equipamento utilizando soluções padrão de Ca e Mg nas concentrações de $0 ; 0,25 ; 0,50 ; 1,00 ; 1,50$ e 2,50 $\mathrm{mg} \mathrm{L}^{-1}$.

\section{Determinação de $P$ e $K$}

Adicionou-se, a $10 \mathrm{~g}$ de solo, $125 \mathrm{~mL}$ de solução extratora de Mehlich (ácido clorídrico com ácido sulfúrico na proporção de 1:10). Agitou-se por $10 \mathrm{~min}$, e deixou-se em repouso por uma noite. Um volume de $25 \mathrm{~mL}$ do sobrenadante foi utilizado para realização de medidas de $\mathrm{P}$ e $\mathrm{K}$.

A $5 \mathrm{~mL}$ do extrato, adicionaram-se $10 \mathrm{~mL}$ de solução de molibdato (ácido sulfúrico concentrado e subcarbonato de bismuto com molibdato de amônio) e ácido ascórbico, agitou-se e deixouse em repouso por $30 \mathrm{~min}$. As medidas de $\mathrm{P}$ foram realizadas em espectrofotômetro UV-vis, Drawell, no comprimento de onda de $660 \mathrm{~nm}$. As medidas de $\mathrm{K}$ foram realizadas, diretamente, no fotômetro de chama, Digimed, utilizando uma curva de calibração com soluções de $\mathrm{KCl}$ nas concentrações de 5; 20; 40; 80 e $120 \mathrm{mg} \mathrm{L}^{-1}{ }^{21}$

\section{Determinação de C}

Adicionaram-se a $1 \mathrm{~g}$ de solo, $10 \mathrm{~mL}$ de solução oxidante de dicromato de sódio. Deixou-se em repouso por $20 \mathrm{~min}$ e fez-se a diluição para $100 \mathrm{~mL}$. A solução ficou em repouso por uma noite e as medidas foram realizadas em espectrofotômetro UV-vis no comprimento de onda de $650 \mathrm{~nm}$. Os valores correspondentes de carbono e de matéria orgânica foram obtidos a partir de tabela de referência, que consiste em valores de absorbância obtidos de curva de calibração, preparada com um conjunto de solos que tiveram a matéria orgânica determinada pelo método Walkley \& Black. ${ }^{22}$

\section{Determinação de $\mathrm{Ne}$ C totais}

Foram maceradas $2 \mathrm{~g}$ de amostras de solo, com pistilo e almofariz, e peneiradas em malha de $0,20 \mathrm{~mm}$. Foram identificadas e armazenados em tubos de plástico de $50 \mathrm{~mL}$. Para a técnica realizada e tipo de amostra, mediram-se de 30 a $40 \mathrm{mg}$ de amostras de solo, utilizando uma balança, Sartorius, com precisão de 0,001 mg. As amostras foram encapsuladas em folhas de estanho, $37 \mathrm{~mm}$ por $37 \mathrm{~mm}$. Tais cápsulas foram alocadas para determinação de $\mathrm{N}$ e C totais por combustão seca em um analisador elementar (CHNOS) no equipamento Elementar Vario EL III. ${ }^{22}$

\section{Determinação de areia, silte e argila}

Uma massa de $40 \mathrm{~g}$ de amostra de solo foi alocada em béqueres de plástico de $600 \mathrm{~mL}$. Para a queima da matéria orgânica, adicionaramse $50 \mathrm{~mL}$ de solução de $\mathrm{H}_{2} \mathrm{O}_{2} 30 \mathrm{v} / \mathrm{v}$, e deixou-se em banho-maria em temperatura de $60{ }^{\circ} \mathrm{C}$, agitando manualmente a solução e repondo a solução de $\mathrm{H}_{2} \mathrm{O}_{2}$ conforme ocorria a sua evaporação. Após 7 dias de aquecimento, e secura total da amostra, as amostras de solo foram maceradas e armazenadas em potes plásticos.

Após, em $20 \mathrm{~g}$ de amostras de solo, adicionaram-se $20 \mathrm{~mL}$ de solução de $\mathrm{NaOH} 1 \mathrm{~mol} \mathrm{~L}^{-1} \mathrm{com} 30 \mathrm{~mL}$ de água deionizada. A solução foi agitada em mesa agitadora por uma noite. A solução foi, então, peneirada em malha $53 \mathrm{~mm}$ e, com o auxílio de água deionizada, foi transferida para uma proveta de $1 \mathrm{~L}$. Adicionaram-se à proveta 10 $\mathrm{mL}$ da solução Calgon (hexametafosfato de sódio), e o volume foi completado até $1 \mathrm{~L}$ com água deionizada. A solução foi agitada, por $30 \mathrm{~s}$, com agitador manual, e retirou-se uma alíquota de $20 \mathrm{~mL}$, de argila + silte a $10 \mathrm{~cm}$ de profundidade, que foi transferida para um cadinho de porcelana identificado. As frações mais finas do solo, silte e argila, foram desagregadas por sedimentação diferencial, portanto, de acordo com a Tabela de correlação entre temperatura e tempo (Lei de Stokes), a solução da proveta permaneceu em repouso por 4 h e $33 \mathrm{~min}$, para ocorrer a decantação de $5 \mathrm{~cm}$ de silte. ${ }^{21}$ Após decorrido o tempo, retirou-se uma alíquota de $20 \mathrm{~mL}$, de argila, a $5 \mathrm{~cm}$ de profundidade e foi transferida para um cadinho de porcelana 
identificado. Todos os cadinhos foram colocados em estufa, à temperatura de $90^{\circ} \mathrm{C}$, por $24 \mathrm{~h}$.

As frações de areia, que ficaram retidas na peneira de $53 \mathrm{~mm}$, foram transferidas para placas de Petri, identificadas e colocadas em estufa, a $50{ }^{\circ} \mathrm{C}$ por uma noite.

Todas as amostras de areia, silte e argila ficaram armazenadas em dessecador até o esfriamento, e as massas foram medidas em balança analítica. ${ }^{21}$

\section{Análise dos agrotóxicos no solo}

Utilizou-se como metodologia de referência o estudo realizado por Lesueur e colaboradores (2008). Neste trabalho, fez-se uma otimização do método, considerando os analitos selecionados para este estudo. ${ }^{23}$

Toda a vidraria utilizada foi limpa em banho ultrassônico e calcinada em mufla por $2 \mathrm{~h}$ em temperatura de $450{ }^{\circ} \mathrm{C}$. Os padrões analíticos foram preparados fazendo-se a dissolução de $1 \mathrm{mg}$ de cada agrotóxico (99\% de pureza, Sigma-Aldrich) em $5 \mathrm{~mL}$ de acetato de etila (grau HPLC, Riedel de Haen/Honeywell). Essa solução foi diluída para obter a concentração de $2 \mathrm{mg} \mathrm{L}^{-1}$, a qual foi analisada no cromatógrafo a gás acoplado a espectrômetro de massas sequencial (CG-EM/EM), utilizando o método TIC Scan, com uma razão massa/carga de 50 a 500. A partir da identificação dos analitos pelas ferramentas do software utilizado, as análises seguiram utilizando as amostras de solo coletadas.

As amostras de solo foram descongeladas em temperatura ambiente e peneiradas em malha 18 mesh, 0,250 mm (Bertel).

Para o estudo de exatidão do método, foram feitas fortificações a $5 \mathrm{~g}$ de solo (coletado na região de estudo, em um ponto onde não se faz aplicação de agrotóxicos ao solo) de alaclor, atrazina, clorpirifós e trifluralina nas concentrações de $2,4,10,18 \mu \mathrm{g} \mathrm{kg}^{-1}$, utilizando $1 \mathrm{~mL}$ de uma solução padrão contendo os quatro agrotóxicos. A determinação dos níveis de concentração para a fortificação foi baseada a partir de pesquisa bibliográfica, pois a concentração neste trabalho está na faixa de $2 \mu \mathrm{g} \mathrm{kg}^{-1}$, inferior à maioria dos trabalhos, sendo um dos diferenciais do presente estudo. A precisão do método foi verificada a partir das replicatas, 3 réplicas para cada nível de fortificação, para obter os valores de desvios-padrões. O procedimento de extração foi realizado por ultrassom $(40 \mathrm{kHz}$, Unique) em temperatura ambiente, com $20 \mathrm{~mL}$ de acetato de etila (grau HPLC, Riedel de Haen/Honeywell), seguida de filtração (membrana 0,45 $\mu \mathrm{m}$, Macherey Nagel, 47 mm diâmetro, GF-1) a vácuo (Tecnal), clean-up em cartuchos de florisil (Sigma-Aldrich), evaporação em rotaevaporador (IKA), reconstituição dos analitos para $1 \mathrm{~mL}$ de acetato de etila e filtração em PVDF/PTFE 0,22 $\mu \mathrm{m}$ (Filtrilo). Observando-se o efeito de matriz, que atua amplificando os sinais dos agrotóxicos quando analisados no extrato do solo, construiu-se uma curva de calibração por superposição de matriz, em triplicata, nas concentrações de 1,$0 ; 5,0 ; 10,0 ; 25,0 ; 50,0 ; 75,0$; e $100,0 \mu \mathrm{g} \mathrm{L}^{-1}\left(0,2 ; 1,0 ; 2,0 ; 5,0 ; 10,0 ; 15,0\right.$ e $\left.20,0 \mu \mathrm{g} \mathrm{kg}^{-1}\right)$. As replicatas das amostras foram analisadas por um cromatógrafo a gás acoplado a espectrômetro massas sequencial, pelo método Monitoramento de Reações Múltiplas (MRM), utilizando-se as razões massa/carga dos íons precursores e íon produtos fornecidos pela biblioteca de dados da marca Agilent. Baseando-se em um método cromatográfico utilizado por Dias et al. (2021), a injeção era por splitless, com coluna não polar SLB-5ms (Supelco), 29,70 $\mathrm{m}$ de comprimento, $0,25 \mathrm{~mm}$ de diâmetro e $0,25 \mu \mathrm{m}$ de espessura de filme. Temperatura do injetor e linha de transferência à $300^{\circ} \mathrm{C}$, analisador à $150^{\circ} \mathrm{C}$, injeção de amostra de $2 \mu \mathrm{L}$ e fluxo de gás Hélio 6.0 de $1,6 \mathrm{~mL} \mathrm{~min}^{-1}$. A programação de temperatura foi: $60^{\circ} \mathrm{C}$ por 1 min, $40{ }^{\circ} \mathrm{C} \mathrm{m^{-1 }}$ até $120^{\circ} \mathrm{C}, 10^{\circ} \mathrm{C} \mathrm{min}^{-1}$ até $280{ }^{\circ} \mathrm{C}$, permanecendo nessa temperatura por $2 \mathrm{~min}$. O tempo total de análise foi, portanto, de 20,5 min para cada amostra. O detector foi o espectrômetro de massas operando a $70 \mathrm{eV}$ e $300^{\circ} \mathrm{C}$. A fonte de ionização utilizada foi a de impacto de elétrons. A temperatura do triplo quadrupolo era de $150{ }^{\circ} \mathrm{C}$. Na cela de colisão foi utilizado gás hélio $6.0 \mathrm{com}$ fluxo de 2,3 mL $\mathrm{min}^{1}$ e nitrogênio $5.0 \mathrm{com}$ fluxo de $1,5 \mathrm{~mL} \mathrm{~min} \mathrm{~m}^{-1}$. A partir dos resultados obtidos pelo software QQQ Quantitative de cromatografia, foram avaliados os analitos de interesse considerando os resultados do método MRM, obtendo valores de resolução dos picos cromatográficos, seletividade, número de pratos teóricos (equações 1, 2 e 3 respectivamente) e linearidade a partir de ajuste linear da curva analítica.

$$
\begin{gathered}
\text { Resolução (Res) }=\frac{\sqrt{\mathrm{N}}}{4} \frac{\alpha-1}{\alpha} \frac{\mathrm{k}}{1+\mathrm{k}} \\
\text { Seletividade }(\alpha)=\frac{\mathrm{k} 2}{\mathrm{k} 1} \\
\text { Número de pratos teóricos }(\mathrm{N})=16\left(\begin{array}{c}
\mathrm{tr} \\
\mathrm{W}
\end{array}\right)^{2}
\end{gathered}
$$

sendo k o fator de retenção (proporção do analito que permanece na fase estacionária em relação à fase móvel), tr o tempo de retenção, e $\mathrm{W}$ a largura da base do triângulo formado pelas tangentes do ponto de inflexão do pico cromatográfico. ${ }^{24}$

Também a partir das equações obtidas pelo ajuste linear, obteve-se os resultados de exatidão (considerando as concentrações utilizadas na fortificação e as recuperadas após extração dos analitos), precisão (RSD\%, obtido pela divisão entre o desvio padrão absoluto pela média das concentrações de cada conjunto de réplicas) e limites de detecção (3,3 vezes a divisão entre o desvio padrão do coeficiente linear pelo coeficiente angular) e de quantificação (10 vezes a divisão entre o desvio padrão do coeficiente linear pelo coeficiente angular). A metodologia de extração e quantificação dos agrotóxicos nas amostras de Lapa foi realizada após a validação do método.

\section{Estudo do comportamento dos agrotóxicos no solo}

A fim de se ter conhecimento sobre o comportamento dos agrotóxicos alaclor, atrazina, clorpirifós e trifluralina, de forma simultânea nas amostras de solo, foram feitos ensaios simulando a presença dos 4 agrotóxicos. Para tanto, utilizaram-se cilindros de vidro $(2,8 \mathrm{~cm}$ de diâmetro, $20 \mathrm{~cm}$ de altura, com uma membrana de nylon no fundo) contendo uma coluna de solo de $10 \mathrm{~cm}$, sendo $5 \mathrm{~cm}$ de solo de superfície e $5 \mathrm{~cm}$ de solo coletado a $20 \mathrm{~cm}$ de profundidade. Utilizaram-se as amostras de solo Conv2 e Conv3. As amostras coletadas em superfície, ocuparam $5 \mathrm{~cm}$ superficiais do tubo de vidro, enquanto que as amostras coletadas a $0-20 \mathrm{~cm}$ de profundidade ocuparam os $5 \mathrm{~cm}$ inferiores do tubo, totalizando $10 \mathrm{~cm}$ de coluna de solo. Um esquema representativo é apresentado na Figura 1.

O estudo foi realizado utilizando 4 tubos: 3 réplicas e 1 controle. No controle não se fez a fortificação com agrotóxicos. Nos 4 tubos foi adicionada água ultrapura, o $\mathrm{pH}$ ajustado para 5,50 e obteve-se a capacidade de campo para cada coluna de solo, que foi o volume de água que ficou contido no solo. Nas 3 réplicas, adicionou-se um volume de $100 \mu \mathrm{L}$ da solução padrão da mistura dos agrotóxicos na concentração de $10 \mu \mathrm{g} \mathrm{kg}^{-1}$, e fez-se ensaios de precipitação, de 7 dias (considerando-se o tempo de meia vida dos agrotóxicos), utilizando água, com pH ajustado a 5,50 e o volume da capacidade de campo de cada réplica. ${ }^{25}$ Após esse período, pesaram-se $5 \mathrm{~g}$ de solo das frações de superfície, $5 \mathrm{~cm}$ e $10 \mathrm{~cm}$ da coluna de solo. Em seguida, fez-se a extração de agrotóxicos das amostras conforme item anterior. ${ }^{23}$ 


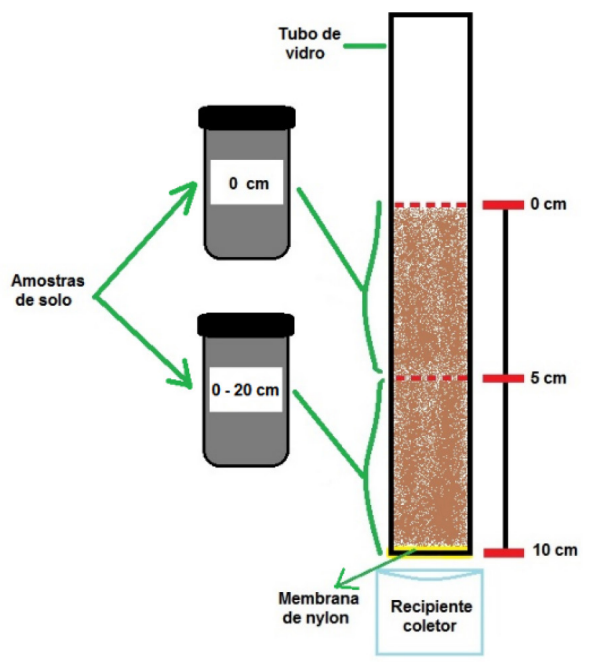

Figura 1. Esquema de construção de colunas de solo para o estudo do comportamento de agrotóxicos

\section{Classificação das amostras de solo por análise de componentes principais (PCA)}

Todos os resultados foram avaliados utilizando a Análise de Componentes Principais (PCA), a fim de verificar as distinções e as semelhanças entre as amostras de solo dos sistemas agroecológico e convencional.

A PCA foi executada em Matlab 7.10 (The MathWorks, Natick, USA) e foi utilizado um toolbox gratuito. Essa rotina permite o cálculo da PCA de uma matriz de dados, em que cada amostra é colocada numa linha e fornece os scores e pesos, assim como a porcentagem de variância descrita em cada componente principal e os scores de uma nova matriz teste.

A partir dos parâmetros químicos, físicos e de fertilidade, foi construída uma matriz de dados acerca de 30 amostras e de 14 variáveis. As amostras foram codificadas, sendo 1 a 15 agroecológicas e 16 a 30 convencionais (sendo 0, 0-20 e 20-40 cm para cada uma). Os dados originais foram autoescalonados e utilizados para gerar o modelo de regressão multivariada.

\section{RESULTADOS E DISCUSSÃO}

\section{Caracterização}

Na Tabela 2 são apresentados os resultados médios de caracterização das amostras de solo dos sistemas agroecológico e convencional.
De modo geral, verifica-se que as amostras de solo de produção convencional possuem maiores teores de areia e menores teores de argila. Considerando os teores de argila e o triângulo textural da Embrapa, todas as amostras apresentam textura média, sendo que o sistema convencional apresenta os menores teores de argila. ${ }^{26}$ Esse fato é correlacionado à quantidade de matéria orgânica no solo, uma vez que tais amostras são pouco alimentadas com matéria orgânica e que o solo não é manejado, de modo que a fração orgânica seja inferior à fração mineral.

Todas as amostras de solo amostradas pertencem à classe dos cambissolos, que se caracteriza por estar em estágio inicial de formação pedogenética, o que é justificado pelos baixos valores de porcentagem de silte e argila e pela relação silte/argila ser superior a 0,3 , ou seja, possui maiores teores de minerais primários que são menos resistentes à intemperização. ${ }^{27,28}$

Nota-se para todas as amostras de superfície que o $\mathrm{pH}$ apresentou menor acidez (valores médios iguais a 5,2 $\pm 0,4$ para agroecologia e 5,3 $\pm 0,8$ para convencional), comparando-se a 20 e $40 \mathrm{~cm}$. Normalmente, o $\mathrm{pH}$ dos solos agrícolas está entre 5,5-6,5. Íons

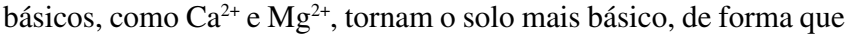
foi possível observar a diminuição dos teores destes elementos de superfície para maiores profundidades, que pode ter contribuído para a acidificação do meio (de 5,14 e 2,56 para 1,46 e 0,50 $\mathrm{cmol}_{\mathrm{c}} \mathrm{dm}^{-3}$

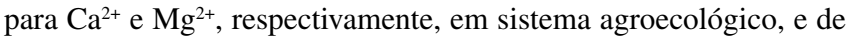
6,50 e 2,26 para 2,04 e $0,86 \mathrm{cmol}_{c} \mathrm{dm}^{-3}$, respectivamente, para sistema convencional). ${ }^{29}$

A CTCefetiva apresentou altos valores para a superfície de amostras de solo do sistema convencional. Comumente, nos solos brasileiros, as propriedades que mais se correlacionam com a sorção de herbicidas básicos e não-iônicos é a CTC do horizonte superficial. ${ }^{30}$ Verifica-se, também, que a CTCefetiva tem relação direta com o $\mathrm{pH}$, pois os valores desses dois parâmetros (indicadores de cargas negativas) são diretamente proporcionais entre si, uma vez que a basicidade do solo está relacionada ao aumento dos teores de $\mathrm{Ca}^{2+}$ que apresentou valores iguais a 5,14 $\mathrm{cmol}_{\mathrm{c}} \mathrm{dm}^{-3}$ para superfície de solo agroeocológico e $6,50 \mathrm{cmol}_{c} \mathrm{dm}^{-3}$ para superfície de solo convencional.

Já o C orgânico está diretamente relacionado ao teor de matéria orgânica, pois presume-se que $58 \%$ da matéria orgânica é composta por C orgânico, sendo esse fator usado como referencial dos teores de matéria orgânica do solo. A quantidade de MOS foi obtida a partir da multiplicação da quantidade de $\mathrm{C}$ orgânico pelo fator de conversão $1,724 .{ }^{30}$

O solo do sistema agroecológico apresenta uma maior concentração de $\mathrm{C}$ orgânico, na faixa de 3 a $8 \mathrm{~g} \mathrm{~kg}^{-1}$. Sabe-se que o sistema agroecológico corrobora para que o teor de fração orgânica

Tabela 2. Resultados médios de caracterização das amostras de solo

\begin{tabular}{|c|c|c|c|c|c|c|c|}
\hline & \multirow{2}{*}{ Parâmetro } & \multicolumn{3}{|c|}{ Agroecologia } & \multicolumn{3}{|c|}{ Convencional } \\
\hline & & Superfície & $0-20 \mathrm{~cm}$ & $20-40 \mathrm{~cm}$ & Superfície & $0-20 \mathrm{~cm}$ & $20-40 \mathrm{~cm}$ \\
\hline \multirow{3}{*}{ Textura } & Areia \% & $54 \pm 20$ & $49 \pm 19$ & $47 \pm 19$ & $67 \pm 4$ & $65 \pm 6$ & $64 \pm 9$ \\
\hline & Silte $\%$ & $25 \pm 9$ & $27 \pm 8$ & $28 \pm 9$ & $23 \pm 4$ & $24 \pm 57$ & $25 \pm 7$ \\
\hline & Argila \% & $27 \pm 12$ & $26 \pm 7$ & $31 \pm 14$ & $18 \pm 1$ & $19 \pm 1$ & $19 \pm 1$ \\
\hline \multirow{2}{*}{ Químicos } & $\mathrm{pH} \mathrm{CaCl}{ }_{2}$ & $5,2 \pm 0,4$ & $4,6 \pm 0,3$ & $4,3 \pm 0,3$ & $5,3 \pm 0,8$ & $4,8 \pm 0,7$ & $4,6 \pm 0,5$ \\
\hline & CTCefetiva $\mathrm{cmol}_{\mathrm{c}} \mathrm{dm}^{-3}$ & $8 \pm 3$ & $4 \pm 2$ & $3 \pm 1$ & $10 \pm 7$ & $5 \pm 3$ & $3 \pm 2$ \\
\hline \multirow{5}{*}{ Fertilidade } & P ppm & $33 \pm 25$ & $9 \pm 1$ & $8 \pm 2$ & $80 \pm 79$ & $11 \pm 5$ & $10 \pm 2$ \\
\hline & $\mathrm{C}$ orgânico $\mathrm{g} \mathrm{kg}^{-1}$ & $45 \pm 7$ & $30 \pm 10$ & $23 \pm 7$ & $41 \pm 8$ & $22 \pm 5$ & $20 \pm 6$ \\
\hline & MOS $\mathrm{g} \mathrm{kg}^{-1}$ & $77 \pm 13$ & $51 \pm 18$ & $40 \pm 12$ & $71 \pm 14$ & $37 \pm 9$ & $35 \pm 10$ \\
\hline & $\mathrm{N}$ total $\%$ & $0,21 \pm 0,06$ & $0,13 \pm 0,05$ & $0,07 \pm 0,05$ & $0,2 \pm 0,1$ & $0,08 \pm 0,05$ & $0,08 \pm 0,03$ \\
\hline & $\mathrm{C}$ total \% & $3 \pm 1$ & $2,2 \pm 0,9$ & $1,0 \pm 0,8$ & $1 \pm 1$ & $1,2 \pm 0,8$ & $1,3 \pm 0,6$ \\
\hline
\end{tabular}


seja maior para o referente tipo de solo, uma vez que a rotação de culturas, a adição de resíduos animais e vegetais e de palhas contribuem para esse ligeiro aumento, enriquecendo o solo. Barbosa e colaboradores (2016) fizeram estudo acerca de amostras de solo de culturas nas quais não se utilizava agrotóxicos, e os teores de MOS encontrados ficaram entre 55 e $64 \mathrm{~g} \mathrm{~kg}^{-1}$, valores que podem ser comparados com os resultados obtidos neste estudo $(40 \pm 12$ a $77 \pm 13 \mathrm{~g} \mathrm{~kg}^{-1}$ ). A quantidade de $\mathrm{C}$ orgânico é ligeiramente maior para o sistema convencional na superfície. Franzluebbers e colaboradores (1996), que fizeram estudo acerca de solos de clima tropical, afirmam que ocorrem maiores teores de matéria orgânica em solos de textura fina em razão das diferentes entradas de $\mathrm{C}$, maior fertilidade do solo e às diferenças na capacidade de armazenamento de água. ${ }^{31}$ Esse fato é equivalente aos resultados de textura, uma vez que as amostras agroecológicas possuem maiores teores de silte ( 2 a $3 \%$ maior), argila (7 a 12\% maior) e C orgânico, frente ao solo do sistema convencional.

Os resultados para $\mathrm{N}$ e $\mathrm{C}$ total foram semelhantes para ambos os sistemas, possivelmente devido à composição dos fertilizantes utilizados nas culturas que contêm esses elementos.

$\mathrm{P}, \mathrm{N}$ total e $\mathrm{C}$ total estão relacionados à fertilidade do solo. $\mathrm{A}$ respeito de cambissolos, a fertilidade é variável, e menor na maior parte do estado do Paraná. Considerando os teores de $\mathrm{P}$ para ambos os sistemas, obteve-se altos valores de desvio padrão, de forma que é possível afirmar que as duas áreas são semelhantes estatisticamente. Contudo, tratando-se de amostras ambientais, é pouco provável que todas as amostras de um mesmo sistema apresentem comportamento semelhante, uma vez que cada solo é tratado de maneira distinta, o que justifica os valores de desvio padrão. Considerando a concentração de $\mathrm{P}$ para ambos os sistemas, os teores foram maiores em superfície, o que indica que há uma grande diferença de concentração de superfície para 20 e $40 \mathrm{~cm}$, ou seja, grande parte do composto pode ser absorvido pelas plantas. Sabe-se que o $\mathrm{P}$ presente no solo pode ter duas fontes: (i) P orgânico, quando se utiliza de esterco animal, e (ii) P inorgânico, proveniente de fertilizantes. Portanto, a presença desse elemento em solo de produção convencional pode ser devido à utilização de fertilizante, uma vez que também pode ser somado ao uso de $\mathrm{P}$ orgânico. Importante destacar que as substâncias húmicas da matéria orgânica podem competir com o P por sítios de sorção nos minerais do solo e, assim, diminuir a estabilização do $\mathrm{P}$ e aumentar a atividade do $\mathrm{P}$ no solo. ${ }^{32}$ Isso é observado no solo de sistema convencional, pois verifica-se que os teores de MOS em ambos os sistemas são semelhantes, mas a proporção de $\mathrm{P}$ que está presente em 20 e $40 \mathrm{~cm}(11 \pm 5$ e $10 \pm 2$ ppm, respectivamente) é muito semelhante àquela de sistema agroecológico ( $9 \pm 1$ e $8 \pm 2$ ppm, respectivamente), embora esse elemento seja mais abundante em superfície de sistema convencional $(80 \pm 79 \mathrm{ppm})$.

\section{Estudo quimiométrico}

Na Figura 2 tem-se o gráfico que explica o modelo de componentes principais, no qual estão contidas as 30 amostras de solo (losangos são agroecológicas e quadrados são convencionais) considerando os parâmetros: pH, CTC efetiva, K, P, C orgânico, areia, silte e argila.

A primeira componente principal (PC1) foi capaz de explicar $57,60 \%$ da variância total dos dados, sendo que a segunda componente foi responsável por $20,36 \%$ da variância. As duas primeiras componentes principais da PCA das variáveis, somaram 77,96\% da variância explicada, refletindo as principais relações geoquímicas das amostras.

Nota-se que as amostras 4, 13, 20, 21 e 22 se distribuíram no primeiro quadrante; as amostras 7, 16, 28 e 29 se distribuíram no segundo quadrante; as amostras $9,11,17,18,23,25,26,27$ e 30 no terceiro quadrante; e as amostras $1,2,5,6,14,15$ e 24 no quarto

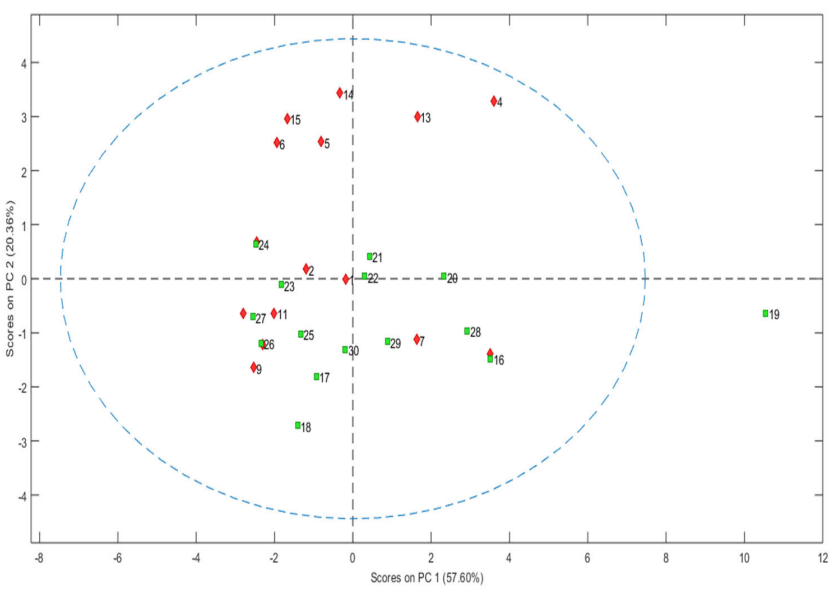

Figura 2. Gráfico em duas dimensões de scores de caracterização de amostras de solo de Lapa, PR. Amostras de1 a 15 (losangos) são agroecológicas e amostras de 16 a 30 (quadrados) são convencionais

quadrante. A amostra 19 apresenta-se com características muitos distintas das demais amostras (podendo ser nomeada como um outlier).

Na Figura 3 tem-se apresentada a influência dos parâmetros através do gráfico de variáveis (loadings) e foi correlacionada com o gráfico de scores através da distribuição dos parâmetros (variáveis) nos quadrantes formados pela intersecção das componentes principais 1 e 2 .

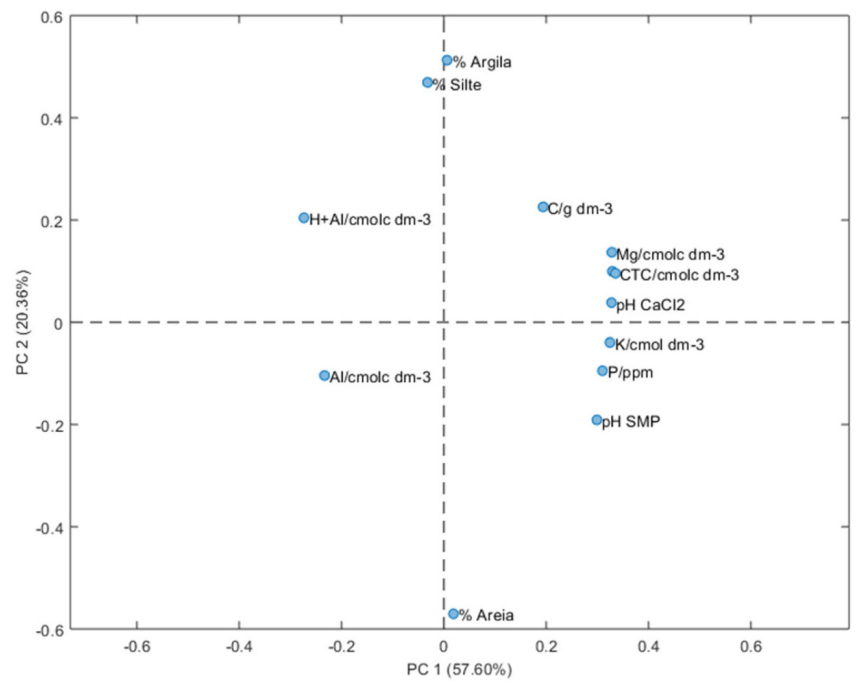

Figura 3. Gráfico de duas dimensões de loadings para caracterização de amostras de solo de Lapa, PR

Verifica-se que as amostras são separadas de acordo com suas diferentes características. Argila e C orgânico encontram-se no mesmo quadrante, de forma que esses dois componentes constituem a fração mais fina do solo, na qual ficam retidos os agrotóxicos. Assim como foi discutido anteriormente, $\mathrm{pH} \mathrm{CaCl}_{2}$ e CTCefetiva apresentam relações diretas, uma vez que os dois parâmetros estão relacionados com as cargas presentes no solo. K e P estão no mesmo quadrante de areia, evidenciando que as maiores concentrações desses nutrientes se encontram na fração mais grossa do solo. E o que separa as amostras no terceiro e no quarto quadrante é, basicamente, os teores de Al, que indica a acidez do solo. Considerando as amostras 19 e 20, verifica-se que as amostras são muito diferentes entre si, uma vez que a amostra 19 é um outlier, considerando que é a amostra que apresenta maiores teores de $\mathrm{K}^{+}\left(2,3 \mathrm{cmol}_{\mathrm{c}} \mathrm{dm}^{-3}\right)$ e de $\mathrm{P}(208,8 \mathrm{ppm})$. 
Portanto, foi possível observar que, embora pertençam a um mesmo ponto amostral, é possível que amostras de solo sejam distintas em suas características.

\section{Determinação de concentrações traço de agrotóxicos nas amostras de solo}

Todos os parâmetros utilizados para a validação do método de extração de agrotóxicos de amostras de solo e identificação e quantificação por cromatografia a gás acoplada a espectrometria de massas, são apresentados a seguir.

\section{Validação cromatográfica}

A partir da injeção de solução padrão de agrotóxicos, em acetato de etila, na concentração de $2,0 \mathrm{mg} \mathrm{L}^{-1}$, para que inicialmente os sinais dos analitos fossem facilmente identificados, obteve-se o cromatograma a seguir (Figura 4).

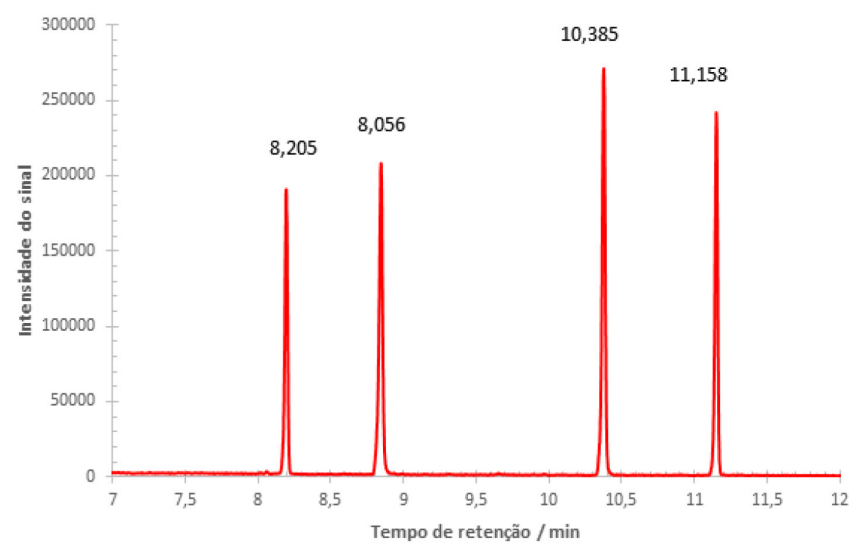

Figura 4. Cromatograma, pelo método TIC Scan, da solução contendo os quatro agrotóxicos, alaclor, atrazina, clorpirifós e trifluralina, na concentração de $2 \mathrm{mg} \mathrm{L}^{-1}$

A partir da ferramenta de espectrometria de massas do software utilizado, os picos correspondentes foram encontrados e integrados, obtendo os espectros de massas. Pela biblioteca do NIST (National Institute of Standards and Technology), os analitos correspondentes foram identificados de acordo com as fragmentações de massas. Trifluralina apresentou tempo de retenção igual a 8,205 min, atrazina igual a $8,856 \mathrm{~min}$, alaclor igual a 10,385 min e clorpirifós igual a 11,158 min. Considerando a programação de temperatura, o tempo total de análise foi igual a 20,5 min.

O cromatograma da curva analítica, construída por superposição de matriz, é apresentado a seguir (Figura 5).

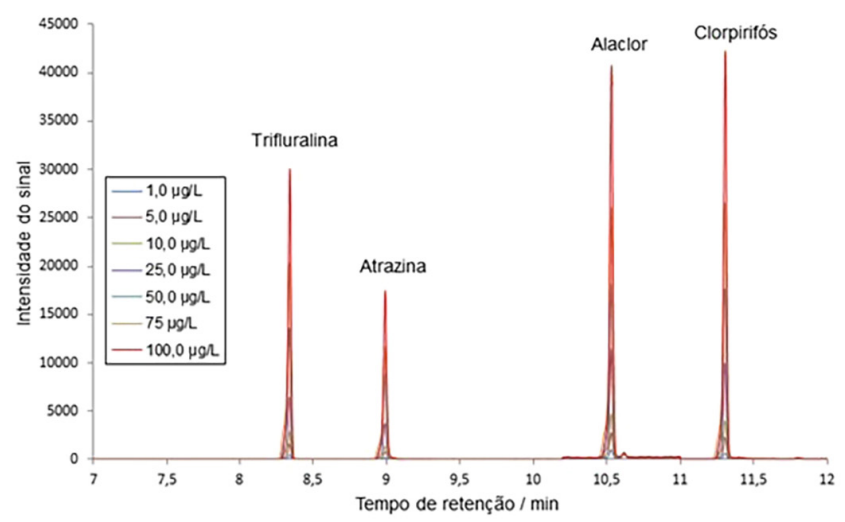

Figura 5. Cromatograma da curva analítica por superposição de matriz, com agrotóxicos nas concentrações de 1,0 a 100,0 $\mu \mathrm{g} \mathrm{L}^{-1}$
A partir dos resultados, calcularam-se os valores de Pratos teóricos, N, Resolução, Res, e Seletividade, $\alpha$, para os picos cromatográficos, os quais são apresentados na Tabela 3.

Tabela 3. Parâmetros cromatográficos calculados considerando os picos de trifluralina, atrazina, alaclor e clorpirifós, por ordem de eluição

\begin{tabular}{cccc}
\hline Composto & $\mathrm{N}$ & $\mathrm{Res}$ & $\alpha$ \\
\hline Trifluralina & 168305,1 & 14,3 & 1,2 \\
Atrazina & 125316,0 & 36,275 & 1,3 \\
Alaclor & 140311,5 & 17,3 & 1,1 \\
Clorpirifós & 196426,2 & 17,3 & 1,1 \\
\hline
\end{tabular}

Verificou-se que o número de pratos teóricos foi superior a 43900 , comum para colunas capilares com comprimento próximo de $30 \mathrm{~m}$, as Resoluções foram superiores a 1,5 e as Seletividades foram maiores que 1 , evidenciando a boa separação dos picos. ${ }^{24}$

\section{Linearidade e sensibilidade}

A partir das respostas para cada nível de concentração da curva analítica, foi realizado o ajuste linear para cada analito, de forma a obter os coeficientes de correlação $\left(r^{2}\right)$, angulares (a) e lineares (b). O gráfico contendo os ajustes lineares é apresentado na Figura 6.

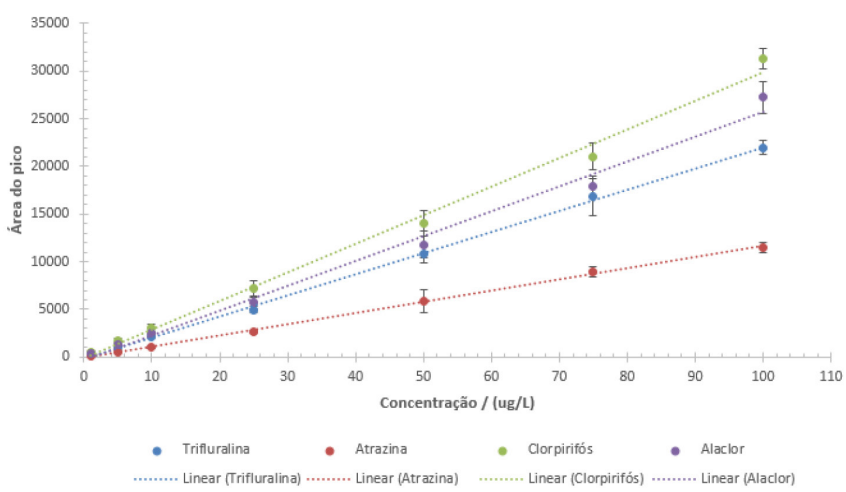

Figura 6. Curvas analíticas para os compostos alaclor, atrazina, clorpirifós e trifluralina, nas concentrações de 1,0 a 100,0 $\mathrm{g} \mathrm{L}^{-1} . \mathrm{N}=3$

Todos os valores de $\mathrm{r}^{2}$ foram iguais a 0,99 , de modo que as equações de regressão linear são estatisticamente significativas. Verifica-se que alaclor e clorpirifós são os analitos que têm maiores coeficientes angulares, ou seja, maiores sensibilidades ao método. Ainda, esses são os mesmos compostos que apresentam maiores intensidades de sinal no cromatograma da Figura 4.

Considerando a equação $y=a x+b$, obteve-se os valores que são apresentados na Tabela 4, onde (a) e (b) são os coeficientes angulares e lineares, respectivamente, juntamente com seus desvios padrões, (s).

Tabela 4. Valores dos coeficientes angular e linear, (a) e (b), e seus respectivos desvios padrões, (s), da equação de ajuste linear para a curva analítica para os agrotóxicos alaclor, atrazina, clorpirifós e trifluralina

\begin{tabular}{ccccc}
\hline Agrotóxico & $\mathrm{a}$ & $\mathrm{s}_{\mathrm{a}}$ & $\mathrm{b}$ & $\mathrm{s}_{\mathrm{b}}$ \\
\hline Alaclor & 87,7 & 0,6 & 30 & 32 \\
Atrazina & 34,89 & 0,06 & -2 & 3 \\
Clorpirifós & 110,8 & 0,9 & 9 & 48 \\
Trifluralina & 68,7 & 0,9 & -79 & 50 \\
\hline
\end{tabular}

\section{Exatidão}

A partir da equação linear e da determinação das concentrações de agrotóxicos nas réplicas de fortificação, foi possível obter os valores médios de recuperações, em (\%), apresentados na Tabela 5. 
Tabela 5. Valores calculados de recuperação (Rec) e respectivos desvios padrões, (s), para os compostos alaclor, atrazina, clorpirifós e trifluralina, considerando as concentrações de fortificação de 2,0;4,0;10,0 e 18,0 $\mu \mathrm{g} \mathrm{kg}^{-1}$. N=3

\begin{tabular}{ccccc}
\hline \multirow{2}{*}{$\begin{array}{c}\text { Fortificação } \\
\left(\mu \mathrm{kg} \mathrm{k}^{-1}\right)\end{array}$} & Alaclor & Atrazina & Clorpirifós & Trifluralina \\
\cline { 2 - 5 } & $\operatorname{Rec}(\%)$ & $\operatorname{Rec}(\%)$ & $\operatorname{Rec}(\%)$ & $\operatorname{Rec}(\%)$ \\
\hline 2,0 & $93 \pm 11$ & $97 \pm 7$ & $98 \pm 10$ & $99 \pm 7$ \\
4,0 & $113 \pm 6$ & $97 \pm 3$ & $92 \pm 3$ & $95 \pm 4$ \\
10,0 & $94 \pm 10$ & $91 \pm 12$ & $89 \pm 10$ & $83 \pm 9$ \\
18,0 & $90 \pm 1$ & $93,9 \pm 0,5$ & $89 \pm 1$ & $86 \pm 3$ \\
\hline
\end{tabular}

Portanto, a recuperações ficaram entre 83 e $113 \%$, dentro dos valores aceitáveis para análise de resíduos em amostras. ${ }^{33}$

\section{Precisão}

A precisão do método foi determinada a partir do cálculo dos desvios padrões relativos (RSD), que são apresentados na Tabela 6.

Tabela 6. Valores de RSD obtidos para alaclor, atrazina, clorpirifós e trifluralina, para cada valor de concentração de fortificação, considerando $n=3$

\begin{tabular}{ccccc}
\hline \multirow{2}{*}{$\begin{array}{c}\text { Concentração } \\
\text { inicial }\left(\mu \mathrm{kg}^{-1}\right)\end{array}$} & Alaclor & Atrazina & Clorpirifós & Trifluralina \\
\cline { 2 - 5 } & RSD $(\%)$ & RSD $(\%)$ & RSD $(\%)$ & RSD $(\%)$ \\
\hline 2 & 11 & 7 & 10 & 7 \\
4 & 6 & 3 & 3 & 4 \\
10 & 10 & 13 & 11 & 10 \\
18 & 2 & 0,6 & 2 & 4 \\
\hline
\end{tabular}

Desse modo, os valores de RSD foram todos inferiores a $20 \%$, sendo aceitos para métodos de análise de resíduos. ${ }^{33}$

\section{$L D$ e $L Q$}

Os valores de limites de detecção e de quantificação, para cada um dos compostos, foram determinados a partir da equação linear da curva analítica e são apresentados na Tabela 7. Os valores são acompanhados dos seus respectivos desvios padrões, (s).

Tabela 7. Valores de LD e LQ obtidos para alaclor, atrazina, clorpirifós e trifluralina, juntamente com seus respectivos desvios padrões

\begin{tabular}{ccc}
\hline Agrotóxico & $\mathrm{LD}\left(\mu \mathrm{g} \mathrm{kg}^{-1}\right)$ & $\mathrm{LQ}\left(\mu \mathrm{g} \mathrm{kg}^{-1}\right)$ \\
\hline Alaclor & $0,01 \pm 0,01$ & $0,04 \pm 0,03$ \\
Atrazina & $0,0028 \pm 0,0006$ & $0,008 \pm 0,002$ \\
Clorpirifós & $0,004 \pm 0,001$ & $0,011 \pm 0,003$ \\
Trifluralina & $0,02 \pm 0,02$ & $0,05 \pm 0,07$ \\
\hline
\end{tabular}

Assim, LD e LQ foram crescentes para atrazina, clorpirifós, alaclor e trifluralina. Masiá et al. (2015) obtiveram os valores para alaclor $\left(10 \mu \mathrm{g} \mathrm{kg}^{-1}\right)$, e atrazina $\left(2,6 \mu \mathrm{g} \mathrm{kg}^{-1}\right)$. Já Polese et al. (2002) obtiveram os valores de LQ de 60 e $20 \mu \mathrm{g} \mathrm{kg}^{-1}$ para trifluralina e atrazina, respectivamente, valores 1200 e 2500 vezes superiores aos encontrados neste estudo, respectivamente. Os valores obtidos por Yang et al. (2010) também foram superiores, 827 e 1481 vezes para atrazina e clorpirifós $\left(6,7\right.$ e $\left.16,3 \mu \mathrm{g} \mathrm{kg}^{-1}\right)$ respectivamente, em relação à esta pesquisa. Chai e colaboradores (2014) obtiveram 2 e $5 \mu \mathrm{g} \mathrm{kg}^{-1}$ de LQ para clorpirifós para dois tipos de solo diferentes. Portanto, é possível observar que este trabalho apresentou LD e LQ inferiores aos encontrados na literatura.

\section{Identificação e quantificação de agrotóxicos nas amostras de solo}

Considerando os resultados de extração de agrotóxicos nas amostras de solo, alaclor e atrazina não foram detectados, enquanto que clorpirifós foi quantificado em Conv3 e a trifluralina em Agro2 e 3 e Conv2.

O alaclor é um composto de uso proibido no estado do Paraná desde o ano de 2013, o que pode justificar a não detecção do mesmo. A atrazina é utilizada por alguns produtores convencionais no Assentamento Contestado. A não identificação de atrazina pode ser devido à rápida transformação deste composto em seus metabólitos que, por sua vez, não são facilmente identificados devido à ausência de seus padrões analíticos. O tempo de meia vida da atrazina é de 60 dias, mas os metabólitos que podem ser gerados, por efeito de degradação microbiana, podem persistir por longo tempo no solo, mas não sendo identificados pelo método apresentado neste estudo..$^{10,15}$ Os resultados são apresentados na Tabela 8.

A trifluralina foi quantificada no ponto Agro2 em superfície nas três campanhas de amostragem. Analisando as coletas, nota-se que a primeira foi semelhante à encontrada na fração de $0-20 \mathrm{~cm}$ da segunda coleta. Possivelmente isso ocorreu devido ao revolvimento do solo, uma vez que o composto não tem tendência de percolar. Já na terceira coleta, a concentração em superfície aumentou consideravelmente, podendo ser devido ao acumulado, pelo menos, em todo o tempo de amostragem.

Em Agro3, o composto foi identificado somente em superfície na primeira coleta, e a não identificação do mesmo em coletas posteriores pode ser devido à volatilização e fotólise rápida do composto. ${ }^{10,34}$

$\mathrm{O}$ fato de trifluralina ter sido identificada em ambientes agroecológicos é preocupante, pois existe a possibilidade de agrotóxicos aplicados em propriedades de produção convencional contaminarem os alimentos de produções agroecológicas.

No Conv2, a concentração de trifluralina diminuiu de superfície para 0-20 cm, reafirmando a não lixiviação do composto. Para esse caso, observando que as concentrações são da mesma ordem de grandeza para os ambientes agroecológicos, é possível que esse ambiente também tenha sido contaminado com trifluralina proveniente de outra propriedade convencional.

A trifluralina é um composto altamente volátil, devido à sua alta pressão de vapor $\left(1,4 \cdot 10^{-2} \mathrm{~Pa}\right)$, de forma que pode ser transportada também pelo ar. ${ }^{10}$ Considerando perdas de compostos contaminantes para o ambiente por volatilidade, Rice e colaboradores (2002) afirmaram em seu estudo que a trifluralina foi perdida na maior quantidade em relação ao aplicado, $12,5 \%$ após 5 dias e 14,1\% após 21 dias. Um segundo fator que compromete a quantificação da trifluralina deve-se à suscetibilidade do composto à fotólise $\left(\mathrm{t}_{1 / 2}\right.$ de 9 $\mathrm{h}$ em água).$^{34}$ Vale ressaltar que não somente a trifluralina, mas todos os outros compostos que são altamente voláteis podem apresentar esse tipo de transporte.

Avaliando quanto à possível retenção de outros agrotóxicos, o ponto Agro2 apresentou o maior valor de CTC efetiva em superfície $\left(12,08 \mathrm{cmol}_{\mathrm{c}} \mathrm{dm}^{-3}\right)$ quando comparado às demais amostras agroecológicas, de forma que possa favorecer a adsorção de substâncias catiônicas, que são capazes de interagir com as cargas negativas presentes no solo. Também, o ponto Conv2 destaca-se por apresentar os maiores valores de $\mathrm{pH}$ e CTC efetiva em todas as profundidades $\left(6,43 ; 5,88 ; 5,06\right.$ e 22,$40 ; 9,81 ; 7,15 \mathrm{cmol}_{\mathrm{c}} \mathrm{dm}^{-3}$; respectivamente), quando comparado à todas as demais amostras. $\mathrm{O}$ aumento do pH da solução do solo causa elevação dos sítios de carga negativa por meio da desprotonação dos sítios de troca de minerais da fração argila e dos grupos funcionais carboxílicos e fenólicos da matéria orgânica, de forma a favorecer a adsorção de 
Tabela 8. Resultados de identificação de clorpirifós e trifluralina em amostras de solo

\begin{tabular}{|c|c|c|c|c|c|c|c|c|}
\hline \multirow{2}{*}{ Amostra } & \multirow{2}{*}{$\mathrm{N}^{\mathrm{o}}$ da amostra } & \multirow{2}{*}{ Profundidade $/ \mathrm{cm}$} & \multicolumn{3}{|c|}{ Clorpirifós/ $\mu \mathrm{g} \mathrm{kg}^{-1}$ de solo } & \multicolumn{3}{|c|}{ Trifluralina/ $\mu \mathrm{g} \mathrm{kg}^{-1}$ de solo } \\
\hline & & & $\mathrm{C} 1$ & $\mathrm{C} 2$ & $\mathrm{C} 3$ & $\mathrm{C} 1$ & $\mathrm{C} 2$ & $\mathrm{C} 3$ \\
\hline \multirow{2}{*}{ Agro2 } & 4 & 0 & - & - & - & $0,28 \pm 0,03$ & $0,09 \pm 0,009$ & $0,5 \pm 0,1$ \\
\hline & 5 & $0-20$ & - & - & - & - & $0,28 \pm 0,06$ & $0,07 \pm 0,02$ \\
\hline \multirow{2}{*}{ Agro3 } & 7 & 0 & - & - & - & $0,12 \pm 0,03$ & - & - \\
\hline & 8 & $0-20$ & - & - & - & - & - & - \\
\hline \multirow{2}{*}{ Conv2 } & 19 & 0 & - & - & - & $0,77 \pm 0,01$ & $0,15 \pm 0,01$ & - \\
\hline & 20 & $0-20$ & - & - & - & $0,08 \pm 0,02$ & $0,06 \pm 0,01$ & - \\
\hline \multirow{2}{*}{ Conv3 } & 22 & 0 & $34 \pm 3$ & $9,6 \pm 0,2$ & $23 \pm 7$ & - & - & - \\
\hline & 23 & $0-20$ & $0,7 \pm 0,1$ & $1,7 \pm 0,3$ & $4,97 \pm 0,04$ & - & - & - \\
\hline
\end{tabular}

C1: Primeira coleta de solos; C2: Segunda coleta de solos; C2: Terceira coleta de solos.

moléculas de carga positiva em sua estrutura. ${ }^{35}$ Ou seja, essa amostra também apresenta a possibilidade de reter, eletrostaticamente, outros agrotóxicos que favoreçam esse tipo de interação, mas que não foram analisados no presente estudo.

No ponto Convencional 3 foi quantificado somente o clorpirifós. Nas três campanhas de amostragem foi possível observar concentrações em superfície. Vale ressaltar que este composto teve concentração $\left(34 \pm 3\right.$ e $\left.23 \pm 7 \mu \mathrm{g} \mathrm{kg}^{-1}\right)$ superior às compreendidas pela faixa de trabalho da curva analítica. Salienta-se que, em superfície, a concentração de clorpirifós diminuiu da primeira para a segunda e aumentou para a terceira coleta, provavelmente devido à reaplicação do composto ao solo. Sabe-se que o clorpirifós é utilizado por alguns produtores do Assentamento Contestado, e é um produto largamente utilizado nas plantações de morango. Nesse sentido, normalmente, cambissolos apresentam os maiores teores de matéria orgânica em superfície, ou seja, no horizonte A, que comumente tem extensão de $30 \mathrm{~cm}$ de profundidade. Além disso, agrotóxicos $\operatorname{com~} \mathrm{k}_{\mathrm{oc}}$ superiores a $300 \mathrm{~mL} \mathrm{~g}^{-1}$ são fortemente adsorvidos pela matéria orgânica do solo. Considerando-se as propriedades físico-químicas do composto, esse possui forte interação com a matéria orgânica do solo, sendo altamente apolar. O clorpirifós apresenta $\mathrm{k}_{\mathrm{oc}}$ igual a $6070 \mathrm{~mL} \mathrm{~g}^{-1}$, o que favorece a sua persistência na porção do solo que contenha matéria orgânica, como é o caso das amostras analisadas de 0 a $20 \mathrm{~cm}$. De 0 a $20 \mathrm{~cm}$, a concentração do composto aumentou da primeira até a terceira coleta. Uma vez que a matéria orgânica diminui no perfil do solo, a mobilidade do composto de superfície para $20 \mathrm{~cm}$ pode ser explicada pelo possível revolvimento do solo feito pelos agricultores entre as campanhas de amostragem, uma vez que o composto é não-ionizável, descartando a mobilidade realizada pela água. Contudo, não foi possível obter informações a respeito dos dias em que se aplicaram agrotóxicos à cultura de morangos, mas sabe-se que a aplicação normalmente é feita com intervalos entre 7 e 10 dias, embora o intervalo de segurança indicado na bula do produto seja de 21 dias. ${ }^{36}$

Considerando as altitudes de cada ponto, apresentadas na Tabela 1, observa-se que não há diferenças muito significativas entre os pontos de sistema agroecológico, de forma que o transporte de agrotóxicos para esses sistemas pode estar mais relacionado ao efeito dos ventos, carreando compostos voláteis pela atmosfera. Já considerando os sistemas Conv2 e Conv3, observa-se que esses pontos amostrais apresentam os menores valores de altitude em comparação com os demais, de forma que é possível afirmar que possam ocorrer transporte e acúmulo de agrotóxicos nesses pontos.

Sobretudo, o solo pode agir como um catalisador ou como um participante das reações químicas que ocorrem com os agrotóxicos. ${ }^{14}$ Portanto, é importante ressaltar que a não detecção ou a baixa quantificação dos agrotóxicos nas amostras de solo também é devida à formação de seus metabólitos, que, por sua vez, não puderam ser identificados no presente estudo.

\section{Comportamento dos agrotóxicos nas amostras de solo}

Na Tabela 9 são apresentados os valores de concentração de agrotóxicos obtidas a partir dos ensaios de simulação de chuva/ precipitação, para os pontos Convencional 2 e Convencional 3.

Os valores de concentração de agrotóxicos foram obtidos a partir da subtração entre as médias das concentrações obtidas nas 3 réplicas e a concentração obtida no tubo denominado controle. Considerandose os valores de concentração de agrotóxicos que foram fortificados ao solo aos valores de concentração que foram encontrados nas diferentes porções do mesmo, pode-se fazer afirmações prévias a respeito do comportamento conjunto desses agrotóxicos.

Para o alaclor nota-se comportamento semelhante em Conv2 e Conv3, ou seja, nas camadas de 0 a $5 \mathrm{~cm}$ apresentou concentrações semelhantes, apresentando maior concentração $\left(1,0 \mu \mathrm{g} \mathrm{kg}^{-1}\right) \mathrm{em} 10 \mathrm{~cm}$ para o ponto Conv2. Vryzas e colaboradores (2012) identificaram a persistência de baixas concentrações de alaclor nas amostras de solução do solo, e o mesmo resultado observado neste trabalho, uma vez que o composto foi identificado em baixas concentrações no solo que sofreu lixiviação. Este composto apresenta baixo valor de $\mathrm{k}_{\mathrm{oc}}$, e caráter não-ionizável e médio potencial de lixiviação de água

Tabela 9. Valores de concentração para alaclor, atrazina, clorpirifós e trifluralina, na profundidade de 0,5 e $10 \mathrm{~cm}$, para os ensaios de simulação de chuva/ precipitação realizados com as amostras de solo de Conv2 e Conv3

\begin{tabular}{|c|c|c|c|c|c|}
\hline Amostra & Profundidade $/ \mathrm{cm}$ & Alaclor $/ \mu \mathrm{g} \mathrm{kg}^{-1}$ de solo & Atrazina $/ \mu \mathrm{g} \mathrm{kg}^{-1}$ de solo & Clorpirifós $/ \mu \mathrm{g} \mathrm{kg}^{-1}$ de solo & Trifluralina/ $\mathrm{g} \mathrm{kg} \mathrm{k}^{-1}$ de solo \\
\hline \multirow{3}{*}{ Conv2 } & 0 & $0,5 \pm 0,4$ & - & $0,5 \pm 0,1$ & $0,5 \pm 0,3$ \\
\hline & 5 & $0,4 \pm 0,2$ & - & $0,4 \pm 0,1$ & $0,5 \pm 0,3$ \\
\hline & 10 & $1,0 \pm 1,0$ & - & $0,7 \pm 0,7$ & $0,9 \pm 0,7$ \\
\hline \multirow{3}{*}{ Conv3 } & 0 & $0,23 \pm 0,05$ & - & $13 \pm 4$ & $0,25 \pm 0,03$ \\
\hline & 5 & $0,1 \pm 0,2$ & - & $5 \pm 5$ & $0,06 \pm 0,07$ \\
\hline & 10 & - & - & $0,7 \pm 0,3$ & $0,02 \pm 0,10$ \\
\hline
\end{tabular}


subterrânea, de forma que a presença do mesmo se deve à interação com a matéria orgânica do solo. ${ }^{10,12,30}$ Para os herbicidas não-iônicos, como alaclor, é possível obter correlação linear positiva entre valores de $\mathrm{k}_{\mathrm{oc}}$ e teores de $\mathrm{C}$ orgânico do solo. Para solos brasileiros, essa correlação é mais acentuada, podendo-se estimar a sorção desses compostos com base nos teores de C orgânico. ${ }^{30}$

Atrazina não foi detectada em nenhuma amostra de solo do referente ensaio. Quando comparado com os 4 analitos de interesse, o composto apresenta baixo valor de Log kow (coeficiente de partição octanol/água 2,7), e maior potencial de lixiviação de água subterrânea. ${ }^{10} \mathrm{Ou}$ seja, dentre os 4 analitos estudados, é o composto que apresenta menor tendência em ficar associado à matéria orgânica do solo, tendo potencial de lixiviar e permanecer no meio hidrofílico. Também de acordo com o estudo de Fenoll et al. (2011), a atrazina está entre os agrotóxicos que apresentam maior lixiviação, e este efeito pode ser potencializado conforme o $\mathrm{pH}$ diminui, o que ocorre com o aumento da profundidade para as amostras analisadas neste estudo. ${ }^{37}$ De acordo com Vryzas et al., o tempo de meia vida de atrazina varia de acordo com profundidade. Neste estudo, os valores de tempo de meia vida da atrazina, em amostras de solo, variaram de 5 a 18 dias nas camadas superficiais e aumentaram à medida que a profundidade do solo aumentou, atingindo os valores de 43 dias na camada de 80 e $110 \mathrm{~cm}$ de profundidade. Tais observações mostram que adsorção, persistência e lixiviação interagem entre si. Além disso, se considerar que o tempo de meia vida do composto é maior conforme se aumenta a profundidade, aumenta-se a probabilidade do mesmo atingir águas subterrâneas. Portanto, considera-se que o tempo de meia vida de atrazina, em geral, é de 60 dias. Patterson et al. (2000) e Close et al. (1998) observaram uma lixiviação mais rápida de atrazina em solos argilosos do que em solos arenosos, fato que também é importante se considerar que as amostras de solo estudadas apresentam textura média quando se considera os teores de argila. Portanto, seriam necessários novos estudos de comportamento de atrazina em camadas inferiores a $10 \mathrm{~cm}$ de solo. A atrazina também é um dos agrotóxicos que sofre rápida transformação para seus metabólitos, podendo ser um dos efeitos que justificam a não identificação do composto em nenhum ensaio.

Fenoll e colaboradores afirmam, também a partir de estudos de lixiviação de agrotóxicos em amostras de solo, que os valores de concentrações obtidos foram crescentes considerando atrazina, alaclor, trifluralina e clorpirifós. Os agrotóxicos não-iônicos não reagem com a água e não apresentam carga elétrica, independentemente do $\mathrm{pH}$ do meio. ${ }^{30}$ Portanto, $\mathrm{pH}$ e CTC são somente consideráveis quando se trata da presença de atrazina no solo, uma vez que os demais analitos estudados não interagem com a água.

Para o clorpirifós, nota-se que em Conv2 passando da superfície até $10 \mathrm{~cm}$ de profundidade, as concentrações foram semelhantes, levando em conta os valores de desvios-padrões. Já em Conv3 a concentração diminuiu conforme aumenta a profundidade. Observa-se comportamento semelhante ao já visto para as amostras individuais de solo. O clorpirifós foi o composto que apresentou maiores valores de concentração $\left(13 \pm 4\right.$ e $\left.5 \pm 5 \mu \mathrm{g} \mathrm{kg}^{-1}\right)$, e esse resultado deve-se às propriedades físico-químicas do composto, uma vez que as mesmas amostras de solo foram avaliadas para os demais compostos. Dentre os quatro agrotóxicos estudados, o clorpirifós é aquele que apresenta o segundo maior valor de $\mathrm{k}_{\mathrm{oc}}$, com pequeno potencial de lixiviação, sendo não-ionizável. ${ }^{10,30} \mathrm{O}$ tempo de meia vida de clorpirifós pode variar, entre 10 e 90 dias, sendo esse fato também determinante na possibilidade de extrair este composto do solo.

A trifluralina apresentou concentrações semelhantes de $0-10 \mathrm{~cm}$ em Conv2. Já em Conv3 apresentou maior concentração na superfície.

A trifluralina caracteriza-se como um composto não-ionizável, apresentando pequeno potencial de lixiviação de água subterrânea e baixo valor de $\mathrm{K}_{\mathrm{ow}} \cdot{ }^{10,30}$ Dessa forma, a presença do composto nas amostras de solo deve-se ao seu alto valor de $\mathrm{k}_{\mathrm{oc}}$, embora esse composto também apresente elevada volatilidade e $t_{1 / 2}$ de $9 \mathrm{~h}$ em água. ${ }^{34}$

De forma geral, a simulação da chuva/precipitação nas amostras de solo apresentou resultados para os agrotóxicos de forma semelhante ao já identificado nas amostras individuais de solo, confirmando que as propriedades físico-químicas dos agrotóxicos, bem como as características do solo, têm grande influência no comportamento ambiental.

\section{CONCLUSÕES}

Considerando os solos de sistemas agroecológico e convencional, foi possível observar que as amostras são diferentes entre si. O solo de sistema convencional apresenta maiores teores de areia e menores teores de argila. $\mathrm{pH}, \mathrm{CTC}$ efetiva, $\mathrm{N}$ total e $\mathrm{C}$ total são equivalentes para os dois sistemas. Teores de C orgânico e MOS são ligeiramente maiores para solo de sistema agroecológico. O solo de superfície de sistema convencional apresentou altos teores de $\mathrm{P}$ quando comparado ao de sistema agroecológico, mas ambos apresentaram equivalência de teores de $\mathrm{P}$ em 20 e $40 \mathrm{~cm}$, pois nessas profundidades a quantidade de $\mathrm{C}$ orgânico e MOS são semelhantes para ambos os sistemas, uma vez que ocorre competição entre matéria orgânica e $\mathrm{P}$ no solo. Os teores de matéria orgânica foram semelhantes aos que eram esperados para solo do tipo cambissolo.

A partir da caracterização de 30 amostras de solo da Lapa, foi possível verificar que a presença de agrotóxicos está relacionada a diferentes fatores, como parâmetros de textura, químicos e de fertilidade, mas, principalmente às propriedades físico-químicas dos agrotóxicos e à quantidade de matéria orgânica no presente no solo.

No estudo quimiométrico foi possível observar que os parâmetros de textura fazem a distinção das amostras, mesmo que permaneçam em um mesmo ponto amostral, uma vez que os parâmetros químicos e de fertilidade foram distribuídos considerando as frações mais grossas e mais finas do solo. Sobretudo, teores de argila e de matéria orgânica auxiliaram na justificativa da presença de trifluralina e de clorpirifós nas amostras de solo analisadas.

A partir das figuras de mérito obtidas, foi possível validar um método de extração, identificação e quantificação de alaclor, atrazina, clorpirifós e trifluralina de amostras de solo agrícola do Assentamento Contestado, Lapa, PR.

Alaclor e atrazina não foram identificados nas amostras de solo, enquanto que trifluralina foi quantificada nos ambientes agroecológicos 2 e 3 e no ambiente convencional 2. Contudo, é possível afirmar a ocorrência de contaminação por agrotóxicos entre ambientes agroecológicos e convencionais. Clorpirifós foi quantificado nos ambientes convencionais 2 e 3 , nos quais se faz o cultivo de morangos, o que justifica a presença do composto no solo.

Através dos ensaios de avaliação do comportamento dos agrotóxicos no solo, verificou-se que as propriedades físico-químicas dos agrotóxicos, bem como as características das amostras, têm influência no comportamento dos mesmos no perfil do solo. Nesses ensaios, clorpirifós e trifluralina apresentam comportamento semelhante aos observados na extração das mesmas amostras. Alaclor apresentou comportamento semelhante para as amostras Conv2 e Conv3. Atrazina não foi identificada, possivelmente por ser um composto que sofre transformação muito rapidamente para seus metabólitos.

Sendo assim, é de extrema importância o estudo acerca da presença e do comportamento de compostos potencialmente tóxicos no ambiente, uma vez que estão interligados aos fenômenos que ocorrem nas interfaces ar-água-solo-alimentos. 


\section{MATERIAL SUPLEMENTAR}

A imagem da distribuição dos 10 pontos amostrais selecionados para o presente estudo está disponível em http://quimicanova.sbq. org.br, na forma de arquivo PDF, com acesso livre.

\section{AGRADECIMENTOS}

Ao MPT-PR, ao LEMASSA, ao LAMEEA, aos Laboratórios de Química e Fertilidade do Solo, de Mineralogia do Solo e de Nutrição de Plantas, da UFPR; à Profa. P. M. Santos pelo auxílio no estudo quimiométrico.

\section{REFERÊNCIAS}

1. Caporal, R. F.; Paulus, G.; Costabeber, J. A.; Agroecologia : uma ciência do campo da complexidade, Brasília, 2009.

2. Galvão, A. A.; Rosas, C. A. R. da F.; Ramos, E. N.; Resumos do XXIII Encontro Nac. Geogr. Agrária, São Cristóvão, Brasil, 2016.

3. de Souza, A. S.; Resumos do XIX Encontro Nac. Geogr. Agrária, São Paulo, Brasil, 2009.

4. Borguini, R. G.; Torres, E. A. F. da S.; UNICAMP-Universidade Campinas-Sistema Bibl. 2006, 13, 64.

5. Ramos, E. N.; Rosas, C. A. R. da F.; Resumos do VIII Simpósio Int. Geogr. Agrária, Curutiba, Brasil, 2017.

6. http://elaa.redelivre.org.br/assentamento-constestado, accessado em abril 2021.

7. Fernandes, G. D. M.; Antonio, V.; Facco, B.; Revista Pegada 2015, 16, 89.

8. Barbosa, J. dos S.; Carducci, C. E.; Kohn, L. S.; Silva, K. do C. R.; da Silva, É. A.; dos Santos, K. L.; Scientia Agraria 2016, 17, 49.

9. Bayer, C.; Bertol, I.; Rev. Bras. Ciênc. Solo 1999, 23, 687.

10. Stell, S. M.; Hopkins, E. H.; Buell, G. R.; Hippe, D. J.; Use and Occurence of Pesticides in the Apalachicola-Flint River basin, Georgia, Alabama, and Florida, U.S. Geol. Surv., 1995.

11. Vryzas, Z.; Papadakis, E. N.; Papadopoulou-Mourkidou, E.; Water Res. 2012, 46, 1979.

12. Inoue, M. H.; Oliveira JR., R. S.; Regitano, J. B.; Tormena, C. A.; Tornisielo, V. L.; Constantin, J.; Planta Daninha 2003, 21, 313.

13. Cheng, Z.; Dong, F.; Xu, J.; Liu, X.; Wu, X.; Chen, Z.; Pan, X.; Zheng, Y.; J. Chromatogr. A 2016, 1435, 115.

14. Javaroni, R. de C. A.; Landgraf, M. D.; Rezende, M. O. O.; Quim. Nova 1999, 22, 58.

15. Albuquerque, M. A.; Shaefer, C. E. G. R.; Foloni, J. M.; Ker, J. C.; Fontes, L. E. F.; R. Bras. Ciênc. Solo 2001, 179.

16. Samadi, S.; Sereshti, H.; Assadi, Y.; J. Chromatogr. A 2012, 1219, 61.
17. Kang, D.; Park, S. K.; Beane-Freeman, L.; Lynch, C. F.; Knott, C. E.; Sandler, D. P.; Hoppin, J. A.; Dosemeci, M.; Coble, J.; Lubin, J.; Blair, A.; Alavanja, M.; Environ. Res. 2008, 107, 271.

18. Gajdár, J.; Barek, J.; Fischer, J.; J. Electroanal. Chem. 2016, 778, 1.

19. Anvisa; Anvisa 2016, 246.

20. EMBRAPA. Em Manual de Procedimentos de Coleta de Amostras em Áreas Agrícolas para Análise da Qualidade Ambiental : Solo, Água e Sedimentos; Filizola, H. F., Gomes, M. A. F., de Souza, M. D., eds.; $1^{\text {a }}$ ed.; Embrapa Meio Ambiente: Jaguariúna, 2006.

21. EMBRAPA; Manual de Métodos de Análise de Solo; $2^{\text {th }}$ ed., Rio de Janeiro, 1997.

22. Marques, R.; Motta, A. C. V.; Análise química do solo para fins de fertilidade, UFPR: Curitiba, 2003.

23. Lesueur, C.; Gartner, M.; Mentler, A.; Fuerhacker, M.; Talanta 2008, 75, 284.

24. Collins, C. H.; Braga, G. L.; Bonato, P. S.; Introdução a Métodos Cromatográficos, Unicamp: Piracicaba, 1997.

25. Khan, M. A.; Brown, C. D.; Sci. Total Environ. 2016, 573, 1573.

26. https://www.embrapa.br/solos/sibcs/atributos-do-solo/outros-atributos, accessado em Abril 2021.

27. Lima, V. C.; de Lima, M. R.; Melo, V. de F.; Conhecendo os principais solos do Paraná: Abordagem para professores do ensino fundamental e médio; $1^{\text {a }}$ ed., Núcleo Estadual do Paraná da Sociedade Brasileira de Ciência do Solo: Curitiba, 2012.

28. Bognola, I. A.; Fasolo, P. K.; Potter, R. O.; Carvalho, A. P.; Bhering, S. B.; Boletim de Pesquisa e Desenvolvimento: Levatamento de Reconhecimento dos Solos da Região Central do Estado do Paraná (área 8); $1^{\text {th }}$ ed., Embrapa Solos: Rio de Janeiro, 2002.

29. https://www.agencia.cnptia.embrapa.br/gestor/soja/arvore/ CONTAG01_34_271020069132.html, accessado em abril 2021.

30. Oliveira Jr, R. S. de; Regitano, J. B. Em Química e Mineralogia do Solo; Melo, V. de F.; Alleoni, L. R. F., eds.; SBCS: Viçosa, 2009.

31. Franzluebbers, A. J.; Haney, R. L.; Hons, F. M.; Zuberer, D. A.; Soil Biol. Biochem. 1996, 28, 1367.

32. Meng, C.; Liu, H.; Wang, Y.; Li, Y.; Zhou, J.; Zhou, P.; Liu, X.; Li, Y.; Wu, J.; Chemosphere 2018, 200, 487.

33. Ribani, M.; Grespan Bottoli, C. B.; Collins, C. H.; Fontes Jardim, I. C. S.; Costa Melo, L. F.; Quim. Nova 2004, 27, 771.

34. Rice, C. P.; Nochetto, C. B.; Zara, P.; J. Agric. Food Chem. Food Chem. 2002, 4009.

35. Alleoni, L. R. F.; Mello, J. W. V.; Rocha, W. S. D. Em Química e Mineralogia do Solo; Alleoni, L. R. F., Melo, V. de F., eds.; SBCS: Viçosa, 2009; pp. 69.

36. https://www.agrolink.com.br/agrolinkfito/produto/klorpan-480-ec_115. html, accessado em abril 2021.

37. Fenoll, J.; Ruiz, E.; Flores, P.; Vela, N.; Hellín, P.; Navarro, S.; J. Hazard. Mater. 2011, 187, 206. 